Article

\title{
From Waste to Multi-Hybrid Layering of High Carbon Steel to Improve Corrosion Resistance: An In-Depth Analysis Using EPMA and AFM Techniques
}

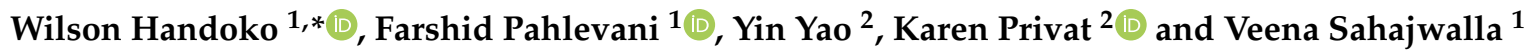 \\ 1 Centre for Sustainable Materials Research and Technology (SMaRT Centre), School of Materials Science and \\ Engineering, UNSW Sydney, Sydney, NSW 2052, Australia \\ 2 Electron Microscope Unit (EMU), Mark Wainwright Analytical Centre, UNSW Sydney, \\ Sydney, NSW 2052, Australia \\ * Correspondence: w.handoko@unsw.edu.au; Tel.: +61-425-958-088
}

Received: 14 June 2019; Accepted: 29 August 2019; Published: 4 September 2019

\begin{abstract}
Corrosion resistance of steel has attracted substantial interest for manufacturing applications to reduce costs corresponding to part failures, unexpected maintenance, and shortening lifespan. Meanwhile, millions of tonnes of slag, non-recyclable glass, and automotive shredder residue (ASR) are discarded into landfills every year, polluting the environment. Combining these two major issues, we delivered an alternative solution to enhance corrosion resistance of high-C steel. In this research, utilisation of these wastes (which were chemically bonded into steel substrate) as sources for production of multi-hybrid layering-including the multi-phase ceramic layer, the carbide layer, and the selective diffusion layer-was successfully achieved by single step surface modification technology. High-resolution topographical imaging by SEM and chemical composition analysis in micron-volume by electron probe micro analyser (EPMA) were performed. Nano-characterisation by atomic force microscopy (AFM) using the PeakForce quantitative nanomechanical mapping (PF-QNM) method was conducted to define Young's modulus value of each phase in detail. Results revealed improvement of corrosion resistance by $39 \%$ and a significantly increased hardness of $13.58 \mathrm{GPa}$. This integrated approach is prominent for economic and environmental sustainability, consolidating industry demands for more profits, producing durable, steel components in a cost effective way to reduce dependency on new resources, and minimising negative impacts to the environment from disposal of wastes to the landfills.
\end{abstract}

Keywords: high carbon steel; waste; multi-hybrid layering; hardness; corrosion resistance; AFM; slag; glass; ASR

\section{Introduction}

In recent years, the utilisation of metal alloy parts has extensively increased in automotive, pharmaceutical, and mining industries, but they are prone to corrosion degradation over time, which can lead to uncertain maintenance cost [1,2]. Improving the metal alloy corrosion resistance properties would increase its serviceability; thus, unnecessary expenses for replacement and maintenance could be eliminated [3,4]. Various attempts have been made to enhance the corrosion resistance properties of steels, such as adding alloying elements (e.g., $\mathrm{Cr}$, Ni), involving multiple steps of heat treatment processes [5], applying surface protective films or coatings [6], and cold spray treatment [7]. These methods are effective for improving the corrosion resistance of steels; however, they have some limitations that need to be considered. Improving corrosion resistance through addition of alloying element steel can sacrifice other properties, such as hardness, tensile strength, and wear resistance [5]. 
Applying a protective film on the steel surface has one major limitation-its adhesion to the steel substrate-which promotes interaction of chemical bond reactions between layers [6]. Using cold spray treatment in high hardness value steels or brittle materials can be a challenge, as this mechanical adhesion via plastic deformation is not as practical as it is for ductile materials [7]. In general, implementing these techniques can increase the energy consumption, including use of additional resources due to involvement of high precision machineries and further processing steps to generate high performance final products, all of which significantly increase production time and cost.

Other techniques such as surface modification are very effective for enhancing corrosion resistance of steels. For instance, deposition of an NiAl bilayer on the steel surface with multiple steps of inter-diffusion heat treatment forms a continuous NiAl surface layer on stainless steel that is able to sustain a supercritical $\mathrm{CO}_{2}$ environment in high temperatures [8]. However, it has some drawbacks that require evaluation, such as high installation cost and incorrect minor settings, which can lead to stress cracking in the cladding [8]. In this research, the single step surface modification method was used to produce multi-hybrid layering-including the multi-phase ceramic layer, the carbide layer, and the selective diffusion layer-derived from various wastes as sources of input and bonded on the surface of high carbon steel with its constituent phases, martensite and retained austenite. The aim of this study was to analyse these generated layers on Young's modulus changes with their correlations to hardness properties, to identify the chemical composition that formed the multi-hybrid layering, and to determine the overall corrosion resistance improvement in comparison with base-material steel. This approach demonstrated that, by utilising waste-integrated input as sources for production of these layers in a cost-effective way, we could reduce the dependency for new resources, thus decreasing the negative impacts on the environment from disposal of wastes to landfills.

Meanwhile, millions of tonnes of metallurgical slag and non-recyclable glass are produced from various industrial waste streams every year, dominated by steelmaking and automotive sectors $[9,10]$. Disposing of these wastes ignores the potential uses of slag and glass as sources of valuable elements or value-added products such as $\mathrm{C}, \mathrm{Si}, \mathrm{Ti}, \mathrm{Mg}$, and $\mathrm{Cr}[11,12]$. Employing these wastes could be beneficial in creating economically viable and environmentally sustainable steel products that would generally reduce the costs associated with the involvement of unnecessary new resources, energy, and other complex processes. This research study is very important to the design of the new advanced applications, as it incorporates two main problems and creates an alternative solution by transforming waste into synthesised layers on high carbon steels through a controlled single step heat treatment process that results not only in improving the corrosion resistance properties and the hardness but also in promoting sustainable manufacturing processes.

In this research, we carefully analysed and compared the corrosion resistance properties on the base-material and after surface modification of high carbon steels through microstructural analysis, chemical composition analysis, electrochemical measurements, and hardness tests. SEM and electron probe micro analyser (EPMA) were utilised for chemical analysis in micron-volume on the edge of the steel surface, where the multi-hybrid layering was located. Advanced atomic force microscopy (AFM) was implemented to measure the Young's modulus value of each phase- the multi-phase ceramic layer fabricated with the carbide layer, the selective diffusion layer (the interface between the carbide layer and the steel substrate), and the main steel substrate - to analyse any alterations against the bulk properties or the steel substrate of the base-material by PeakForce quantitative nanomechanical property mapping (PF-QNM) mode. However, it is worth noting that the AFM method has historically been utilised to investigate nano-mechanical properties of soft materials such as collagen fibrils [13] and membranes of living cells [14]. Scarce research has addressed specimens with very hard surfaces. Electrochemical corrosion tests were performed through the Tafel polarisation method to compare the corrosion rate of the base-material and the "outer layer" (the multi-phase ceramic layer); thus, the percentage of protection efficiency could be calculated. Other mechanical properties were measured by Vickers hardness test to analyse the hardness properties on the cross-sections of the steel samples. 


\section{Materials and Methods}

\subsection{Material Preparation}

High carbon steel with a chemical composition of $1.00 \mathrm{C}, 0.97 \mathrm{Mn}, 0.60 \mathrm{Cr}, 0.20 \mathrm{Si}$, and $0.06 \mathrm{Ni}$ (wt \%) was used in this research. Samples were precisely cut to $11 \mathrm{~mm} \times 11 \mathrm{~mm} \times 3 \mathrm{~mm}$ by Struers Accutom-50 (Struers, Rødovre, Denmark) at low cutting speed to prevent heat transfer that could possibly change its microstructure. To generate surface modification from waste input, slag with 38.3 $\mathrm{Fe}_{2} \mathrm{O}_{3}, 30.3 \mathrm{CaO}, 12.2 \mathrm{SiO}_{2}, 7.3 \mathrm{MgO}, 6.7 \mathrm{MnO}, 2.0 \mathrm{Cr}_{2} \mathrm{O}_{3}$, and balanced (wt \%) were consumed and mixed with waste glass and a mixture of plastics from automotive shredder residue (ASR). The mix covered all the surfaces of the steel in the ceramic crucible before heat treatment began. The heat treatment process was conducted at a temperature of $900{ }^{\circ} \mathrm{C}$ for a dwelling time of $2 \mathrm{~h}$ with a constant argon (Ar) flow at the rate of $1 \mathrm{~L} / \mathrm{min}$ to mimic the inert condition. It was then quenched in cold water. A schematic diagram is presented in Figure 1. The steel sample that was covered by a mixture of wastes was loaded into a furnace at $900{ }^{\circ} \mathrm{C}$. Three different layers were grown from the steel substrate and were classified as the selective diffusion layer, the carbide layer, and the multi-phase ceramic layer. Further investigation of bonding in the steel substrate can be found in the Discussion Section. All steel specimens were cut, ground up to 4000 grit by Struers Tegramin-30 (Struers, Rødovre, Denmark), polished up to $1 \mu \mathrm{m}$ by Struers Rotopol-22 (Struers, Rødovre, Denmark), ultrasonically cleaned (Unisonics Australia, Brookvale, Australia), and completely dried by Struers Drybox-2 (Struers, Rødovre, Denmark). A $\%$ Nital etching solution was used to reveal the microstructures.

\subsection{Analytical Methods}

Microstructural imaging and microanalysis of the chemical composition of the multi-hybrid layer was carried out by SEM and EPMA analysis with the JEOL JXA-8500F (JEOL Inc., Peabody, MA, USA). An advanced AFM (Bruker, Karlsruhe, Germany) method was implemented to analyse different Young's modulus (E) values of each phase. Accordingly, the most applicable method (in principle) to conduct such a study was the AFM in the PeakForce quantitative nanomechanical mapping mode, PF-QNM. The method corresponded to the acquisition of force curves that were registered in every pixel of the reconstruction image. Next, the given parameters-for example, the tip dimension and the cantilever spring constant-were evaluated, thus data quantification of the nano-mechanical properties of each section area was feasible. The Derjaguin-Muller-Toporov (DMT) stiffness fit model was used to analyse the retracting curve $[15,16]$ for the spherical indenter, which contributed to adhesion influences between the steel surface and the tip according to the expression:

$$
F=\frac{4}{3} E^{*} \sqrt{(R d)^{3}}+F_{a d h}
$$

where $F$ refers to applied force, $R$ is for tip radius, $d$ can be defined as deformation value at applied force, $F_{a d h}$ is the optimum adhesion force, and $E^{*}$ is called the effective elastic modulus, which is classified as:

$$
\frac{1}{E^{*}}=\frac{\left(1-v^{2}\right)}{E}+\frac{\left(1-v_{i}^{2}\right)}{E_{i}}
$$

Thus, $E(\mathrm{v})$ and $E_{i}(\mathrm{v})$ refer to the Young's modulus/Poission's ratio between the indenter and the surface of the sample in the sequence. PF-QNM mode was employed to determine the Young's modulus of the multi-phase ceramic layer in 300-400 GPa, the selective diffusion layer in 200-300 GPa, and the main steel substrate in 180-250 GPa ranges on the cross-section area. Due to AFM cantilever size restriction, it was not possible to scan this very thin carbide layer. The mean Young's modulus distribution value was measured three times and compiled and measured by NanoScope Analysis 1.7 and Gwyddion (64 bit) software. 


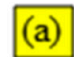

(a)

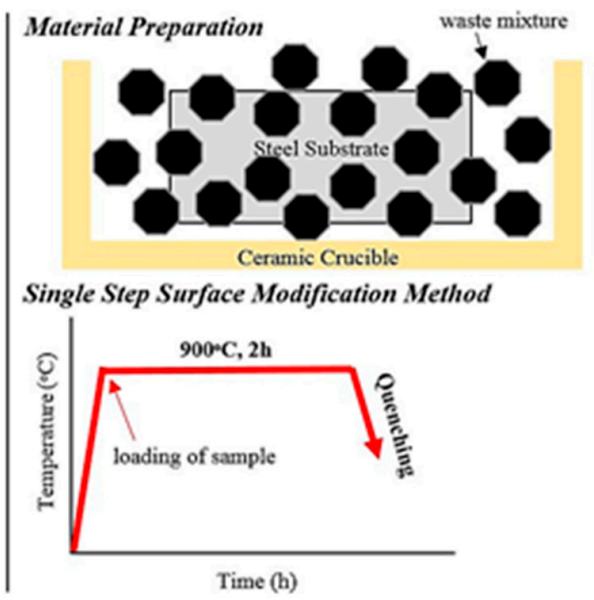

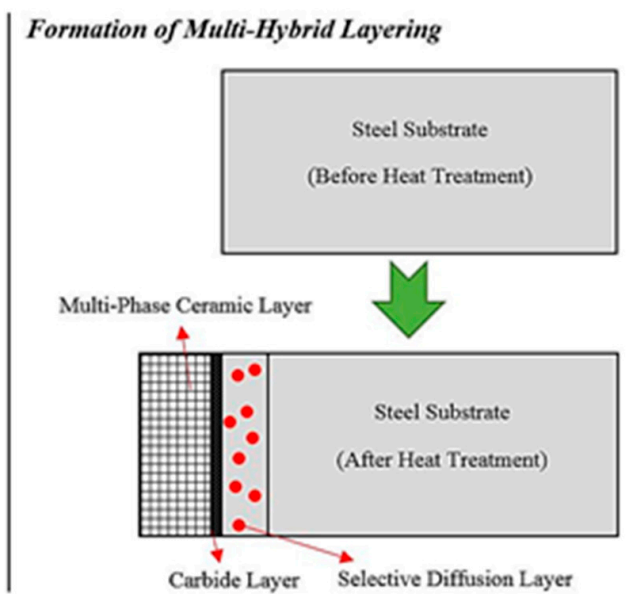
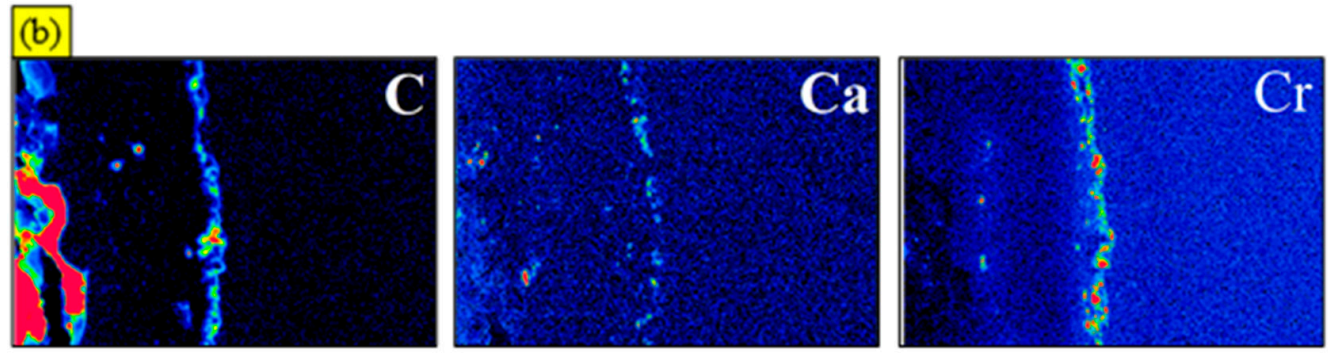

High
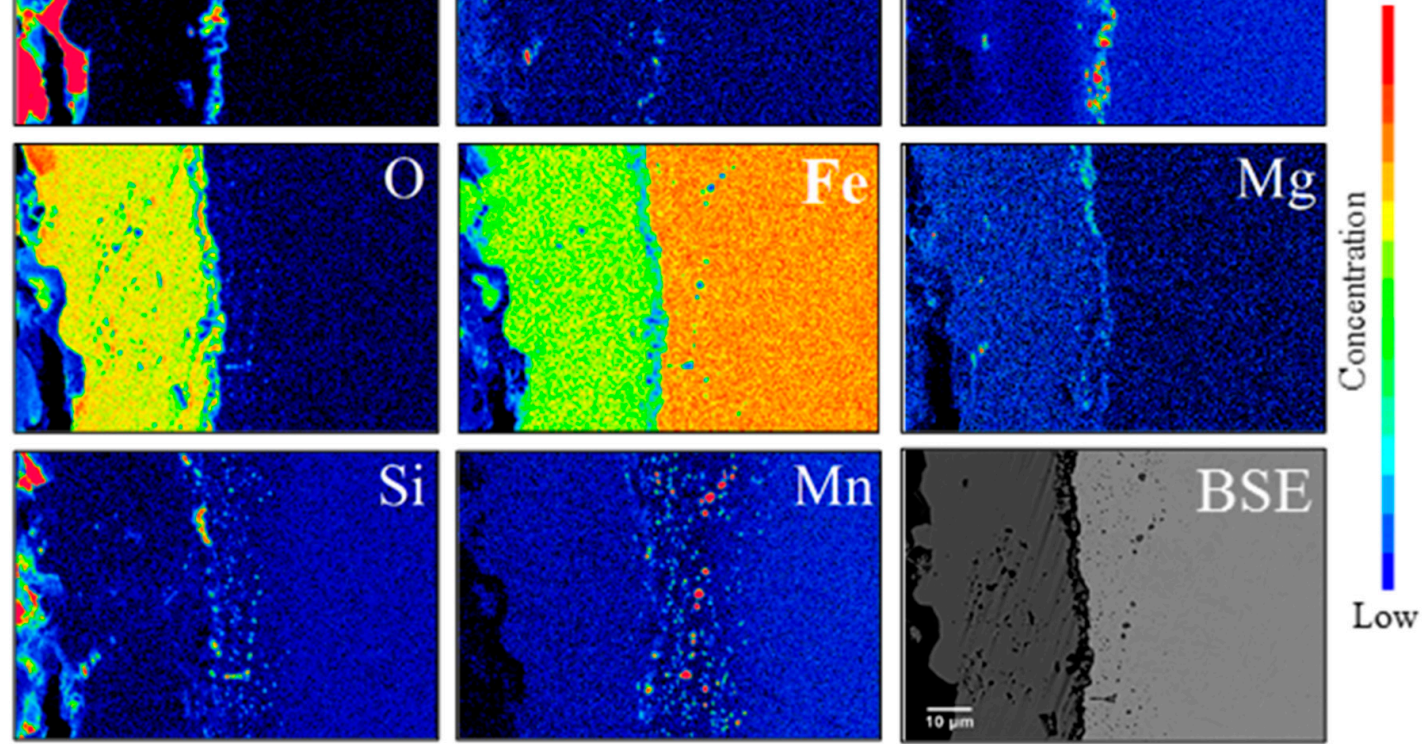

Figure 1. Schematic diagram of (a) multi-hybrid layering formation process on the surface of high carbon steel on (b) with SEM [backscattered electron (BSE) mode] and electron probe micro analyser (EPMA) analysis for $\mathrm{C}, \mathrm{Ca}, \mathrm{Cr}, \mathrm{O}, \mathrm{Fe}, \mathrm{Mg}$, $\mathrm{Si}$, and $\mathrm{Mn}$ at the cross-sectional area.

Electrochemical experiments were demonstrated by using Versatile Multipotentiostat VSP-300 (EC-Lab v.11.02 software) (EC-Lab@, Claix, France). Three-electrode configuration was utilised in a flat corrosion cell. A base-material high carbon steel sample and a modified surface sample of high carbon steel were used for the working electrode. The surfaces of the examined specimens were delimited by the O-ring to achieve a tested area of $1 \mathrm{~cm}^{2}$. The reference electrodes were $\mathrm{Hg} / \mathrm{Hg}_{2} \mathrm{Cl}_{2}$ or saturated calomel electrode (SCE), and platinum electrode was used for the auxiliary electrode. The $3.5 \mathrm{wt} \%$ $\mathrm{NaCl}$ was prepared as an electrolyte that was created from deionised water at room temperature $\left(24 \pm 1^{\circ} \mathrm{C}\right)$. For Tafel polarisation measurements, the open circuit potential (OCP) equilibrium with immersion for $2 \mathrm{~h}$ was collected as the corrosion potential value, $\mathrm{E}_{\text {corr }}$. The curve was charted by sweeping the given potential between $-250 \mathrm{mV}$ and $250 \mathrm{mV}$ with a scan rate of $0.4 \mathrm{mV} / \mathrm{s}$. 
A mechanical hardness test was implemented in 1HV Vickers measurement as per standard procedure of ASTM E-140 on each section-the multi-phase ceramic layer with the carbide layer, the selective diffusion layer, and the steel substrate—by Struers DuraScan-20 (Struers, Rødovre, Denmark).

\section{Results and Discussions}

The bonding of multi-hybrid layering in the steel substrate occurred during the heat treatment process, which attributed to the disintegration of organic compounds and the production of $C$-saturated gas by ASR. Covalent bonds of $\mathrm{C}-\mathrm{C}$ in polymers began to decompose, and reduction reactions occurred. An illustration of this was when $\mathrm{C}$ reacted with $\mathrm{O}_{2}$ in iron (III) oxide $\left(\mathrm{Fe}_{2} \mathrm{O}_{3}\right)$, magnesium oxide (MgO), and silicon dioxide $\left(\mathrm{SiO}_{2}\right)$, mainly from waste slag and glass, to generate $\mathrm{CO}$ and $\mathrm{CO}_{2}$. In general, there were three phenomena that occurred on the interface between the waste and the steel substrate during the heat treatment process. Firstly, there was formation of a selective diffusion layer; the existing Mn in the steel reacted to $\mathrm{C}$, which diffused into the steel from ASR to form various manganese-based type carbides, such as $\mathrm{Mn}_{3} \mathrm{C}$ and $\mathrm{Mn}_{5} \mathrm{C}_{2}$.

Secondly, there was formation of a very thin carbide layer on top of the selective diffusion layer from the reduction of $\mathrm{CaO}, \mathrm{Cr}_{2} \mathrm{O}_{3}$, and $\mathrm{SiO}_{2}$ to form different types of $\mathrm{Ca}, \mathrm{Cr}$, and Si-based carbides. The Ca element in the Fe-matrix had a primary advantage of reducing the volume fraction of $\mathrm{O}$ and $\mathrm{S}$-based inclusions in deoxidation and desulphurisation processes. As $\mathrm{Fe}$ and $\mathrm{Cr}$ have a very good chemical bond, including wettability angle, the $\mathrm{Cr}$ (mostly from the steel and the slag) synthetically bonded to the substrate in the exothermic process [17]. Similarly, the Fe-Si bond, which has stronger bonding properties than the $\mathrm{Fe}-\mathrm{C}$ bond [18], simply led to synthesising in the steel substrate.

Thirdly, there was formation of a multi-phase ceramic layer that consisted of Fe-Mg-O from the reduction of $\mathrm{Fe}_{2} \mathrm{O}_{3}$ in slag. In the two-stage reduction reaction, $\mathrm{Fe}_{2} \mathrm{O}_{3}$ and $\mathrm{CO}$ formed $\mathrm{FeO}$, which reacted to $\mathrm{MgO}$ to form the co-oxide phase. Additionally, a continuous reaction occurred on $\mathrm{FeO}$ with $\mathrm{CO}$ to form Fe particles. Formation of the ionic bond, $\mathrm{MgO}$, in the Fe matrix meant the $\mathrm{Fe} / \mathrm{MgO}$ layer could now occur, as it had distinctive surface free energy of $\mathrm{MgO}\left(1.1 \mathrm{~J} / \mathrm{m}^{2}\right)$ and $\mathrm{Fe}\left(2.9 \mathrm{~J} / \mathrm{m}^{2}\right)$ from the atomic structure model [19]. Another factor of this formation was the presence of $\mathrm{FeO}$ was not able to form in Fe particles at room temperature, but $\mathrm{MgO}$ barrier growth was feasible [19]. This was because $\mathrm{Mg}$ acted in a catalytic role to stimulate the oxidation reaction of $\mathrm{Fe}$ particles on the $\mathrm{Fe}-\mathrm{MgO}$ interface $[19,20]$. In the deposition process, an $\mathrm{MgO}$ single crystal source could decompose as the $\mathrm{Mg}$ element and the $\mathrm{O}_{2}$ molecules served $\mathrm{Mg}$ as catalysts for production of $\mathrm{FeO}[19,20]$. A schematic diagram of these formations is presented in Figure 1a. Previous research proved the existence of $\mathrm{H}_{2}$ in the system can escalate the reduction speed of the metallic phase with Fe present as the catalyst involved in the formation of th ehybrid layer. By nature, $\mathrm{H}_{2}$ has very tiny atom size and a high level of reactivity properties with $\mathrm{O}_{2}$, which increases the reduction speed of oxides [21]. Another factor that supported the reduction speed rate was the reaction between $\mathrm{H}_{2}$ and $\mathrm{C}$ to form $\mathrm{CH}_{4}$ [21].

The different chemical composition of the hybrid layer and the diffused phase to the main substrate on the cross-section of the steel as seen in SEM [in backscattered electron (BSE) mode] and EPMA analysis are presented in Figure $1 \mathrm{~b}$. EPMA microanalysis mapping of $\mathrm{C}, \mathrm{Ca}, \mathrm{Cr}, \mathrm{O}, \mathrm{Fe}, \mathrm{Mg}, \mathrm{Si}$, and $\mathrm{Mn}$ elements visibly showed the chemical bond of the multi-hybrid layering to high carbon steel. It was clear that $\mathrm{C}, \mathrm{Ca}, \mathrm{Cr}$, and $\mathrm{Si}$ formed on top of the selective diffusion layer that robustly bonded between the multi-phase ceramic layer and the steel substrate. The presence of a high level of concentrated Fe-Mg-O as a primary compound on the multi-phase ceramic layer had a direct impact on corrosion resistance and hardness properties. The carbide layer could act as the "secondary protection" after the multi-phase ceramic layer of the Fe-Mg-O-base was removed by applied friction, which led to good wear resistance properties, since the chemically bonded layer could better resist forces compared to the physically bonded layer. Analysis on its nanomechanical properties was defined by AFM in PF-QNM mode to analyse the Young's modulus value on the hybrid layer up to the steel substrate.

Nanomechanical characterisation by AFM with PF-QNM method was performed on the cross-section of high carbon steel samples. The Young's modulus value on the base-material high 
carbon steel is presented in Figure 2, while steel after surface modification or with multi-hybrid layering is represented in Figure 3. SEM images are presented as a guide for the corresponding AFM analysis area; it clearly revealed that the microstructures consisted of martensite and retained austenite phases on both the base-material and the multi-hybrid layering steel near the edge area of the samples. All AFM analyses of Young's modulus results were without etched conditions. This AFM was employed to determine Young's modulus (E) values through the PF-QNM method with the DMT stiffness fit model. In addition, very low level loads were applied to prevent the risk of tip deterioration and contamination. A section of base-material (200 $\mu \mathrm{m}$ from the edge of the steel surface) was carried out through the AFM instrument using the PF-QNM technique to provide an E value simultaneously and continuously from contacted surface.

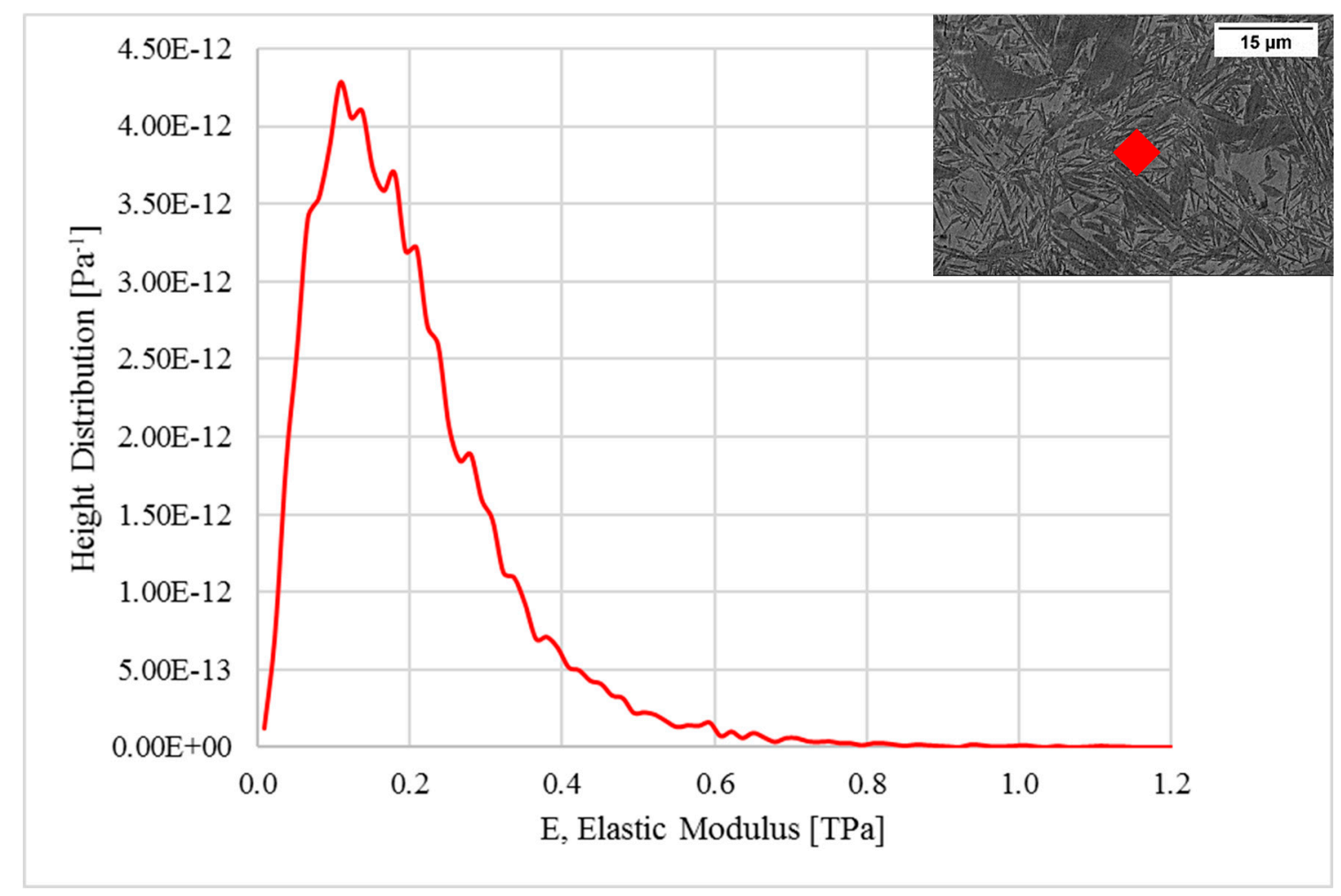

Figure 2. Average Young's modulus distribution graph by PeakForce quantitative nanomechanical mapping (PF-QNM) with the Derjaguin-Muller-Toporov (DMT) fit model on steel substrate or base-material before surface modification. 


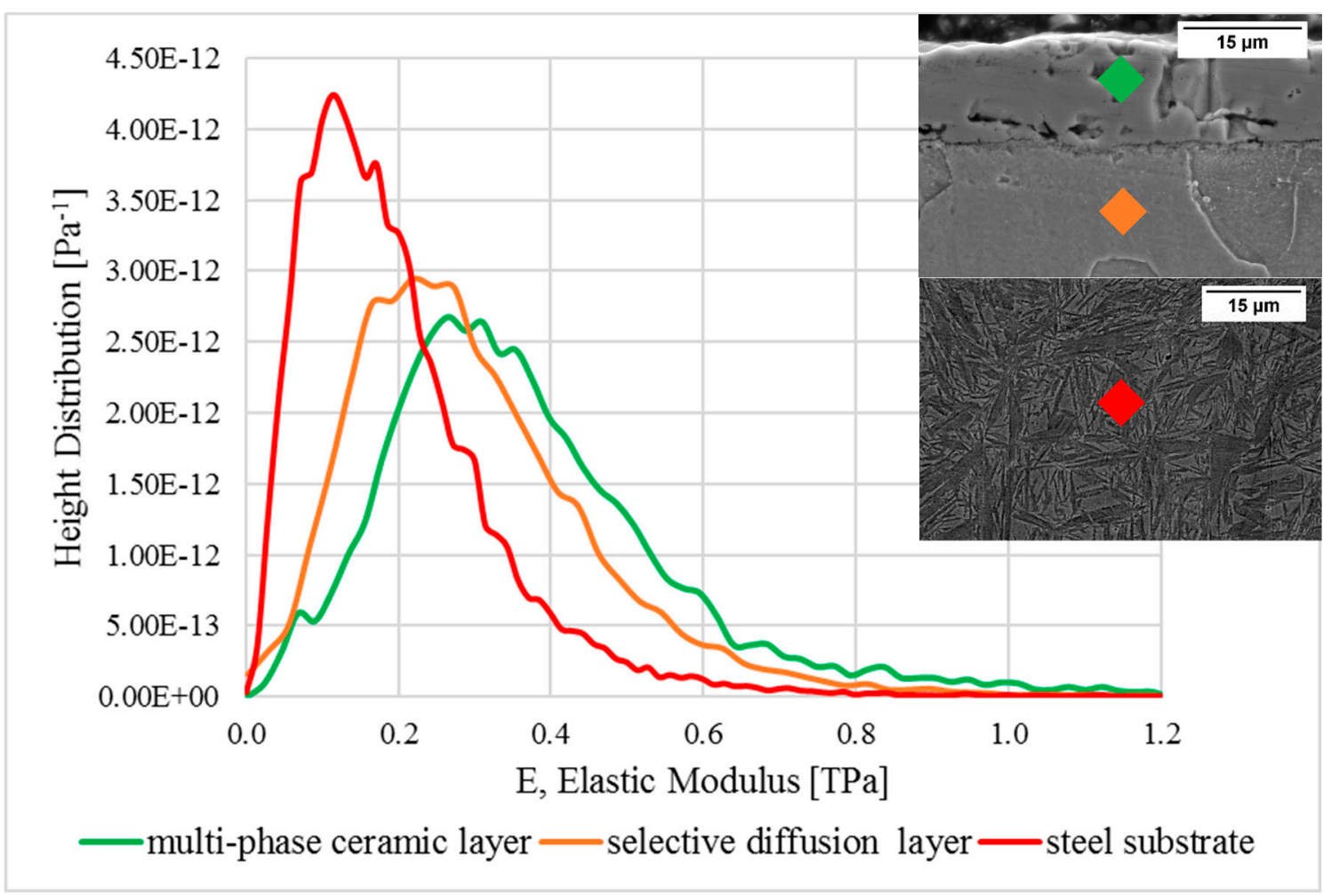

Figure 3. Average Young's modulus distribution graph by PF-QNM with the DMT fit model steel on steel after surface modification of the multi-hybrid layering steel, where green refers to the multi-phase ceramic layer, orange refers to the selective diffusion layer, and red refers to the steel substrate.

The average E value was calculated based on the acquired graph in the TPa unit that covered a $5 \mu \mathrm{m}$ $\times 5 \mu \mathrm{m}$ area. The base-material sample accounted for 204.0 GPa for its E value, in which it performed close to what is typical of most steels at around 200.0 GPa [22]. Moreover, the PF-QNM method was applied to the modified surface high carbon steel sample in which each section was investigated using SEM images as a guide. For this modified surface, the average E value was approximately $359.3 \mathrm{GPa}$ on the ceramic surface layer, followed by $278.0 \mathrm{GPa}$ on the diffused phase and 200.4 GPa on the steel substrate. It can be stated that the obtained Young's modulus for the multi-phase ceramic layer was a value similar to the alumina-like $\left(\mathrm{Al}_{2} \mathrm{O}_{3}\right)$ properties, around 360.0 GPa [23]. The selective diffusion layer formed a composite characteristic between $\mathrm{E}$ values of alumina and steel, whereas on the main steel substrate, it remained unchanged for approximately $200.0 \mathrm{GPa}$, in agreement with the typical Young's modulus ranges of steel. The increased Young's modulus value of this compared to the steel substrate was attributed to the presence of the dominant Fe-Mg-O combination that had good corrosion resistance and mechanical hardness nature [24,25], considering this layer was fabricated with the carbide layer (C, Ca, Cr, and Si elements). A similar behaviour on the Mn-based selective diffusion layer offered higher hardness. Summary of the E value with deviation results in the DMT fit model is exhibited in Table 1. 
Table 1. Young's modulus parameters from PF-QNM method with the DMT fit model.

\begin{tabular}{ccc}
\hline Sample-ID & Young's Modulus (GPa) & Standard Deviation (GPa) \\
\hline $\begin{array}{c}\text { Steel Substrate (Base-Material, } \\
\text { Before Surface Modification) } \\
\text { Multi-Phase Ceramic Layer } \\
\text { (After Surface Modification) }\end{array}$ & 204.0 & 20.92 \\
$\begin{array}{c}\text { Selective Diffusion Layer (After } \\
\text { Surface Modification) } \\
\quad \text { Steel Substrate }\end{array}$ & 359.3 & 17.12 \\
$\quad 278.0$ & 20.34 \\
(After Surface Modification) & 200.4 & 18.72 \\
\hline
\end{tabular}

Electrochemical tests were conducted to provide qualitative data for the overall corrosion intensity before and after surface modification on dual-phase high carbon steel samples. The corrosion test method was performed to each individual potentiodynamic polarisation curve. The corrosion intensity, $\mathrm{i}_{\mathrm{corr}}$, from the intersection between the anodic slope (right portion during discharging) presented as a metal deposition reaction, and the cathodic slope (left portion during charging) was exhibited as a hydrogen evolution reaction perpendicularly crossed through the corrosion potential, $\mathrm{E}_{\text {corr }}$. A comparison of the Tafel extrapolation plot between the base-material and the modified surface (tested surface on the multi-phase ceramic layer) on high carbon steel immersion contact with $3.5 \mathrm{wt} \%$ $\mathrm{NaCl}$ solution as the electrolyte is compiled in Figure 4. The improvement of the corrosion resistance properties is indicated by the lower $\mathrm{i}_{\text {corr }}$ rate and the more positive $\mathrm{E}_{\text {corr }}$ value.

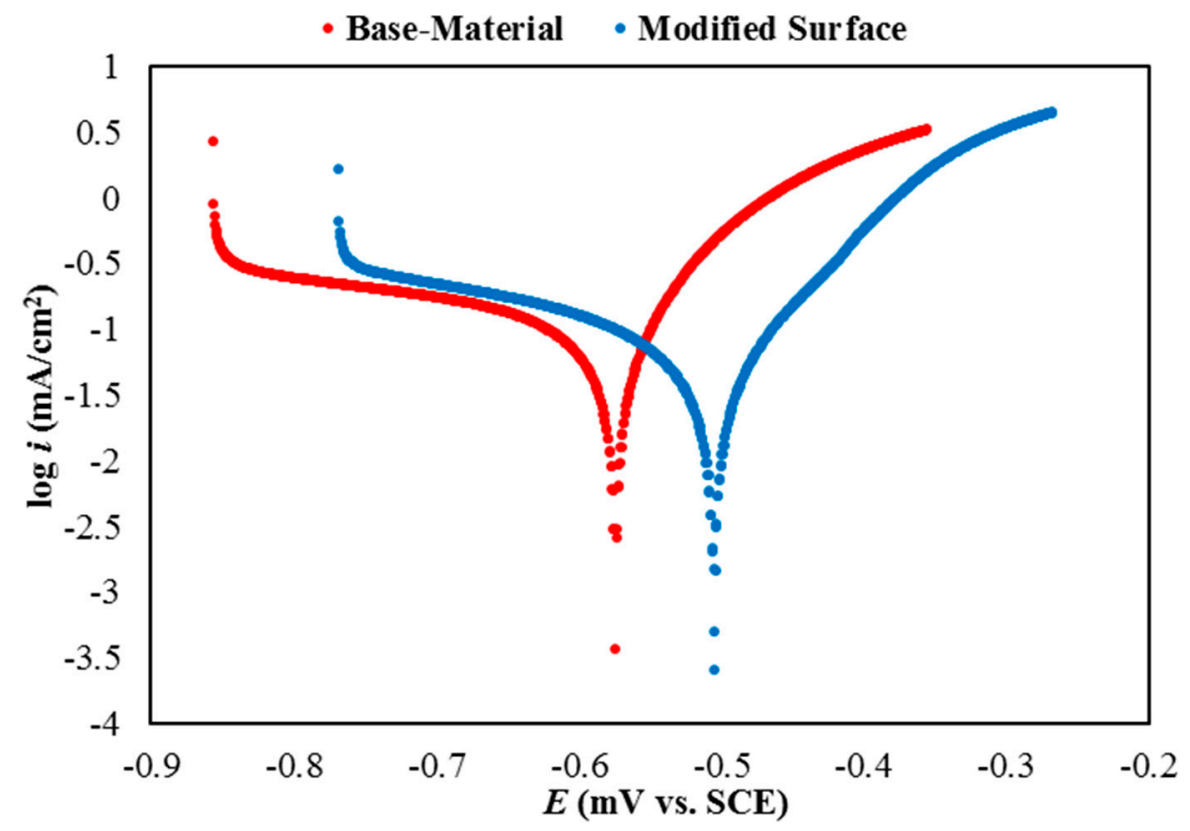

Figure 4. Tafel polarisation curves for the base-material and the modified surface (multi-hybrid layering) on high carbon steel immersed in $3.5 \mathrm{wt} \% \mathrm{NaCl}$ solution.

From this diagram, it can be summarised that the $i_{\text {corr }}$ value of the modified surface sample had significantly less than the base-material, $0.0186 \mathrm{~mA} / \mathrm{cm}^{2}$ and $0.282 \mathrm{~mA} / \mathrm{cm}^{2}$, respectively. Furthermore, overall $\mathrm{E}_{\text {corr }}$ value after surface modification was approximately $13.81 \%$ more positive on the noble side compared to the base-material. This critical discrepancy could be correlated to different corrosion behaviours on the generated hybrid layer through heat treatment. Recent studies proved that the base-material showed preferential attack on retained austenite followed by the martensite phase [26,27]. This was due to the martensitic phase being more stable and less susceptible to corrosion damage over this period, since the Fe percentage in martensite is lower than in retained austenite [26,28]. 
This means that martensite possesses higher levels of $C$ than austenite. Previous studies by Atom Probe Tomography (APT) and stacking fault energy (SFE) methods [28,29] demonstrated that it can act as a "cathode", while austenite acts as an "anode" [26,27]. On the other hand, martensite has a highly packed structure [body-centred tetragonal (bct)], and the absence of cementite enables it to be more corrosion resistant than austenite ( $\gamma$-Fe) [face-centred cubic (fcc)] [26,27]. Similarly, for the main substrate with multi-hybrid layering, it showed similar corrosion behaviours as the base-material, as the heat treatment process was carefully controlled to avoid changes to its bulk properties; thus, the microstructures had identical volume fractions of martensite and retained austenite phases. Other aspects that drove the corrosion mechanisms on certain phases were due to the dissolution of iron atoms and the lack of retained austenite stability [26,27].

Overall corrosion mechanisms for these steels could possibly be pitting and boundary-to-boundary, or so-called grain boundary corrosion. As a result, the Fe-MgO multi-phase ceramic layer, the carbide layer, and the selective diffusion layer could act as a few protective barriers for corrosion protection and could minimise the risk of direct penetration into the main substrate of the steel. The percentage of protection efficiency was calculated to measure the effectiveness of the generated multi-hybrid layer on the surface of high carbon steel.

Quantitative data were recorded to determine the $E_{\text {corr }}$ and the $i_{\text {corr }}$ values before and after surface modification of high carbon steel, as presented in Table 2. Calculation of the polarisation resistance $R_{p}$ can be expressed through Stern-Geary [30], and the percentage of protection efficiency $P_{E F}$ can be expressed by the standard equation [31].

$$
\begin{gathered}
R_{p}=\frac{1}{2.303} * \frac{i_{\text {corr }} * b_{a} * b_{c}}{\left(b_{a}+b_{c}\right)} \\
P_{E F}=\frac{\left.R_{p}^{-1} \text { (base }- \text { material }\right)-R_{p}^{-1}(\text { surface modification })}{R_{p}^{-1}(\text { surface modification })}
\end{gathered}
$$

where $b_{a}$ and $b_{c}$ represent the anode and the cathode section of Tafel slopes $(\Delta E / \log (\mathrm{i}))$, respectively. These results were used to calculate the PEF for the modified surface of high carbon steel. From the results, approximately $39.08 \%$ of the protective multi-hybrid layering had a propensity towards corrosion attack, thus there was improvement in corrosion resistance properties from the outer surface of high carbon steel after heat treatment. Further mechanical hardness tests were conducted to observe different hardness values on each phase after surface modification in comparison with the base-material.

Table 2. Polarisation parameters for base-material and modified surface high carbon steels.

\begin{tabular}{ccccc}
\hline \multirow{2}{*}{ Sample-ID } & \multicolumn{3}{c}{ Electrochemical Corrosion Measurements } & \multirow{2}{*}{$\boldsymbol{P}_{\mathrm{EF}} \mathbf{( \% )}$} \\
\cline { 2 - 4 } & $\boldsymbol{E}_{\text {corr }}(\mathbf{m V}$ vs. SCE) & $\boldsymbol{i}_{\text {corr }}\left(\mathbf{m A} / \mathbf{c m}^{2}\right)$ & $\boldsymbol{R}_{\mathbf{p}} \mathbf{( k \Omega \cdot \mathbf { c m } ^ { 2 } )}$ & \\
\hline Base-Material & $-577 \pm 8$ & $0.282 \pm 0.012$ & 13.87 & - \\
Modified Surface & $-507 \pm 11$ & $0.0186 \pm 0.0015$ & 0.346 & 39.08 \\
\hline
\end{tabular}

Hardness properties of the base-material and multi-hybrid layering on high carbon steel were investigated by standard Vickers method, and comparisons of the average hardness values in HV and GPa conversion units are presented in Table 3. The base-material sample was 7.65 GPa, which was in agreement with typical high carbon steel ranges [32,33]. On the other hand, the multi-phase ceramic layer achieved a $13.58 \mathrm{GPa}$ hardness value, which was closed to $96 \%$ purity of the $\mathrm{Al}_{2} \mathrm{O}_{3}$ hardness group [34,35]; the selective diffusion layer exhibited around a $9.73 \mathrm{GPa}$ hardness value, and its steel substrate hardness value remained almost unaltered against the base-material for approximately $7.64 \mathrm{GPa}$. With the precisely maintained heat treatment process, it can be concluded that 
the mechanical properties of the base-material and the main steel substrate after surface modification remained unchanged.

Table 3. Vickers hardness values for high carbon steel samples before and after surface modification.

\begin{tabular}{ccc}
\hline Sample-ID & Hardness (HV) & in GPa \\
\hline $\begin{array}{c}\text { Steel Substrate (Base-Material, } \\
\text { Before Surface Modification) }\end{array}$ & $780 \pm 10$ & 7.65 \\
$\begin{array}{c}\text { Multi-Phase Ceramic Layer } \\
\text { (After Surface Modification) }\end{array}$ & $1385 \pm 19$ & 13.58 \\
$\begin{array}{c}\text { Selective Diffusion Layer (After } \\
\text { Surface Modification) } \\
\quad \text { Steel Substrate }\end{array}$ & $992 \pm 14$ & 9.73 \\
(After Surface Modification) & $781 \pm 12$ & 7.64 \\
\hline
\end{tabular}

Moreover, transformation of the multi-hybrid layer from waste-integrated inputs as sources had a nearly doubled increased hardness value compared to the base-material. The main reason for this was the presence of the $\mathrm{Mg}-\mathrm{O}$ compound in the Fe matrix with the combination of the hard Fe element characteristics, which improved both the corrosion resistance and the hardness properties of high carbon steel. This included the presence of $\mathrm{C}, \mathrm{Ca}, \mathrm{Cr}$, and $\mathrm{Si}$ elements from the carbide layer. Presence of manganese carbide in the steel substrate on the selective diffusion layer substantially increased the overall hardness value of high carbon steel. The use of waste-integrated input as sources for multi-hybrid layering successfully improved the corrosion resistance and the hardness performance of high C steel.

\section{Conclusions}

Formation of multi-hybrid layering that chemically bonded on the surface of high carbon steel was successfully developed by using slag, non-recyclable glass, and ASR as input sources in a single step surface modification method without changing bulk properties. There were three distinct layers: the multi-phase ceramic layer, the carbide layer, and the selective diffusion layer. SEM and EPMA analysis showed that different layers with distinctive features and chemical compositions visibly presented synthetic bonding on the overall multi-hybrid layering on the surface of high carbon steel. This included the multi-phase ceramic layer with the $\mathrm{Mg}-\mathrm{O}$ compound in th eFe matrix, the presence of a thin carbide layer containing $\mathrm{C}, \mathrm{Ca}, \mathrm{Cr}$, and $\mathrm{Si}$, and a selective diffusion layer that was created from the Mn-based carbide. From AFM perspectives, th emulti-phase ceramic layer performed with similar Young's modulus values to $\mathrm{Al}_{2} \mathrm{O}_{3}$-like properties (approximately $359.3 \mathrm{GPa}$ ), whereas the selective diffusion layer was around $278.0 \mathrm{GPa}$, and the main steel substrate remained unchanged at 200.4 GPa. The electrochemical measurement (the Tafel method) revealed that the percentage of protection efficiency accounted for $39.08 \%$ improvement compared to the base-material. With correlation to Young's modulus measurements, the Vickers quantitative data showed an increasing hardness value up to $13.58 \mathrm{GPa}$, while the diffused phase showed about $9.73 \mathrm{GPa}$, and main steel substrate remained at about 7.64 GPa. This improvement of corrosion resistance and hardness could extend the lifespan of the high carbon steel that is commonly used in chemical and mining applications. It was found that the bulk properties ( $200 \mu \mathrm{m}$ from the edge of the steel surface) remained unaltered. Therefore, these results highlight that corrosion resistance improved (including hardness performance) through the utilisation of various waste streams as valuable sources for production of multi-hybrid layering, promoting cost effectiveness while simultaneously minimising dependency on natural resource demands for protective coating and alloying elements and ultimately reducing the negative impacts on the environment from disposal of various wastes to landfills.

Author Contributions: W.H. designed and performed experiments and data analysis. F.P. performed experiments and critically analysed the data. Y.Y. performed AFM analysis. K.P. performed EPMA analysis. V.S. supervised 
the study and gave recommendations to revise manuscript. W.H. wrote the manuscript and all authors analysed data, discussed the results, read and approved the final manuscript.

Acknowledgments: This research was funded by Australian Government Research Training Program (RTP) and Australian Research Council's Industrial Transformation Research Hub funding scheme (project IH130200025). We gratefully acknowledge the technical support provided by UNSW Mark Wainwright Analytical Centre-Electron Microscope Unit in UNSW Sydney.

Conflicts of Interest: The authors declare no conflict of interest.

\section{References}

1. Tewary, N.; Kundu, A.; Nandi, R.; Saha, J.; Ghosh, S. Microstructural characterisation and corrosion performance of old railway girder bridge steel and modern weathering structural steel. Corros. Sci. 2016, 113, 57-63. [CrossRef]

2. Yu, L.; François, R.; Dang, V.H.; L'Hostis, V.; Gagné, R. Distribution of corrosion and pitting factor of steel in corroded RC beams. Constr. Build. Mater. 2015, 95, 384-392. [CrossRef]

3. Yaro, A.S.; Abdul-Khalik, K.R.; Khadom, A.A. Effect of $\mathrm{CO}_{2}$ corrosion behavior of mild steel in oilfield produced water. J. Loss Prev. Process. Ind. 2015, 38, 24-38. [CrossRef]

4. Tavakoli, H.; Khoie, S.M. An electrochemical study of the corrosion resistance of boride coating obtained by thermo-reactive diffusion. Mater. Chem. Phys. 2010, 124, 1134-1138. [CrossRef]

5. Isfahany, A.N.; Saghafian, H.; Borhani, G. The effect of heat treatment on mechanical properties and corrosion behavior of AISI420 martensitic stainless steel. J. Alloy. Compd. 2011, 509, 3931-3936. [CrossRef]

6. Xiang, Z.; Datta, P. Effects of pack composition on the formation of aluminide coatings on alloy steels at 650 ${ }^{\circ}$ C. J. Mater. Sci. 2005, 40, 1959-1966. [CrossRef]

7. Kumar, S.; Jyothirmayi, A.; Wasekar, N.; Joshi, S.; Joshi, S. Influence of annealing on mechanical and electrochemical properties of cold sprayed niobium coatings. Surf. Coat. Technol. 2016, 296, 124-135. [CrossRef]

8. Kim, S.H.; Subramanian, G.O.; Kim, C.; Jang, C.; Park, K.M. Surface modification of austenitic stainless steel for corrosion resistance in high temperature supercritical-carbon dioxide environment. Surf. Coat. Technol. 2018, 349, 415-425. [CrossRef]

9. Carvalho, S.; Vernilli, F.; Almeida, B.; Demarco, M.; Silva, S. The recycling effect of BOF slag in the Portland cement properties. Resour. Conserv. Recycl. 2017, 127, 216-220. [CrossRef]

10. Al-Zubaid, A.B.; Shabeeb, K.M.; Ali, A.I. Study the Effect of Recycled Glass on the Mechanical Properties of Green Concrete. Energy Procedia 2017, 119, 680-692. [CrossRef]

11. Handoko, W.; Pahlevani, F.; Emmanuelawati, I.; Sahajwalla, V. Transforming automotive waste into TiN and TiC ceramics. Mater. Lett. 2016, 176, 17-20. [CrossRef]

12. Mayyas, M.; Pahlevani, F.; Handoko, W.; Sahajwalla, V. Preliminary investigation on the thermal conversion of automotive shredder residue into value-added products: Graphitic carbon and nano-ceramics. Waste Manag. 2016, 50, 173-183. [CrossRef] [PubMed]

13. Schulze, M.; Rogge, M.; Stark, R.W. Atomic force microscopy measurements probing the mechanical properties of single collagen fibrils under the influence of UV light in situ. J. Mech. Behav. Biomed. Mater. 2018, 88, 415-421. [CrossRef] [PubMed]

14. Gaveau, A.; Coetsier, C.; Roques, C.; Bacchin, P.; Dague, E.; Causserand, C. Bacteria transfer by deformation through microfiltration membrane. J. Membr. Sci. 2017, 523, 446-455. [CrossRef]

15. Derjaguin, K.L.; Muller, V.M.; Toporov, Y.P. Effect of contact deformation on the adhesion of particles. J. Colloid Interface Sci. 1971, 53, 314-326. [CrossRef]

16. Heu, C.; Berquand, A.; Elie-Caille, C.; Nicod, L.; Nicod, L.P. Glyphosate-induced stiffening of HaCaT keratinocytes, a Peak Force Tapping study on living cells. J. Struct. Boil. 2012, 178, 1-7. [CrossRef]

17. Eich, S.; Schmitz, G. Embedded-atom study of grain boundary segregation and grain boundary free energy in nanosized iron-chromium tricrystals. Acta Mater. 2018, 147, 350-364. [CrossRef]

18. Windus, C.; Sujishi, S.; Giering, W.P. Relative iron-carbon and iron-silicon bond strengths in derivatives of (.eta.-cyclopentadienyl) dicarbonyliron. J. Am. Chem. Soc. 1974, 96, 1951-1952. [CrossRef] 
19. Tusche, C.; Meyerheim, H.L.; Jedrecy, N.; Renaud, G.; Ernst, A.; Henk, J.; Bruno, P.; Kirschner, J. Oxygen-Induced Symmetrization and Structural Coherency inFe/MgO/Fe(001)Magnetic Tunnel Junctions. Phys. Rev. Lett. 2005, 95, 176101. [CrossRef]

20. Wang, S.; Han, G.; Yu, G.; Jiang, Y.; Wang, C.; Kohn, A.; Ward, R. Evidence for FeO formation at the Fe/MgO interface in epitaxial TMR structure by X-ray photoelectron spectroscopy. J. Magn. Magn. Mater. 2007, 310, 1935-1936. [CrossRef]

21. Zhang, Y.; Chao, S.; Wang, X.; Han, H.; Bai, Z.; Yang, L. Hierarchical Co9S8 hollow microspheres as multifunctional electrocatalysts for oxygen reduction, oxygen evolution and hydrogen evolution reactions. Electrochim. Acta 2017, 246, 380-390. [CrossRef]

22. Chen, E.; Leung, C.K. A coupled diffusion-mechanical model with boundary element method to predict concrete cover cracking due to steel corrosion. Corros. Sci. 2017, 126, 180-196. [CrossRef]

23. Miyake, K.; Hirata, Y.; Shimonosono, T.; Sameshima, S. The Effect of Particle Shape on Sintering Behavior and Compressive Strength of Porous Alumina. Materials 2018, 11, 1137. [CrossRef] [PubMed]

24. Ciria, M.; Proietti, M.G.; Corredor, E.C.; Coffey, D.; Begué, A.; De La Fuente, C.; Arnaudas, J.I.; Ibarra, A. Crystal structure and local ordering in epitaxial Fe100-Ga/MgO(001) films. J. Alloy. Compd. 2018, 767, 905-914. [CrossRef]

25. Xu, Y.; Li, Y.; Yang, J.; Sang, S.; Wang, Q. Fabrication of MgO-NiO-Fe2O3 materials and their corrosion in Na3AlF6-AlF3-K3AlF6 bath. J. Alloy. Compd. 2017, 723, 64-69. [CrossRef]

26. Man, C.; Dong, C.; Kong, D.; Wang, L.; Li, X. Beneficial effect of reversed austenite on the intergranular corrosion resistance of martensitic stainless steel. Corros. Sci. 2019, 151, 108-121. [CrossRef]

27. Park, I.-J.; Kim, S.-T.; Lee, I.-S.; Park, Y.-S.; Moon, M.B. A Study on Corrosion Behavior of DP-Type and TRIP-Type Cold Rolled Steel Sheet. Mater. Trans. 2009, 50, 1440-1447. [CrossRef]

28. Hossain, R.; Pahlevani, F.; Quadir, M.Z.; Sahajwalla, V. Stability of retained austenite in high carbon steel under compressive stress: an investigation from macro to nano scale. Sci. Rep. 2016, 6, 34958. [CrossRef]

29. Gouné, M.; Danoix, F.; Allain, S.; Bouaziz, O. Unambiguous carbon partitioning from martensite to austenite in Fe-C-Ni alloys during quenching and partitioning. Scr. Mater. 2013, 68, 1004-1007. [CrossRef]

30. Stern, M. and Geary, A.L. Electrochemical polarization I. A theoretical analysis of the shape of polarization curves. J. Electrochem. Soc. 1957, 104, 55-63. [CrossRef]

31. Bockris, J.; Reddy, A.K.N. Modern Electrochemistry; Kluwer Academic Publishers: New York, NY, USA, 2000.

32. Tao, Q.; Wang, J.; Fu, L.; Chen, Z.; Shen, C.; Zhang, D.; Sun, Z. Ultrahigh hardness of carbon steel surface realized by novel solid carburizing with rapid diffusion of carbon nanostructures. J. Mater. Sci. Technol. 2017, 33, 1210-1218. [CrossRef]

33. Ueji, R.; Inoue, T. Acceleration of diffusional transformation in a high-carbon steel layer composed of a sandwich-like clad steel sheet. Mater. Sci. Eng. A 2019, 764, 138217. [CrossRef]

34. Chen, M.; Bai, Z.; Tan, S. Microstructure and friction behavior of polymeric composite coatings on alumina/aluminum composite. Surf. Coat. Technol. 2002, 151, 478-482. [CrossRef]

35. Monticelli, C.; Balbo, A.; Zucchi, F. Corrosion and tribo corrosion behaviour of thermally sprayed ceramic coatings on steel. Surf. Coat. Technol. 2011, 205, 3683-3691. [CrossRef]

(C) 2019 by the authors. Licensee MDPI, Basel, Switzerland. This article is an open access article distributed under the terms and conditions of the Creative Commons Attribution (CC BY) license (http://creativecommons.org/licenses/by/4.0/). 